\title{
BMJ Global Health Does expanding primary healthcare improve hospital efficiency? Evidence from a panel analysis of avoidable hospitalisations in 5506 municipalities in Brazil, 2000-2014
}

\author{
Everton Nunes da Silva, ${ }^{2}$ Timothy Powell-Jackson ${ }^{1}$
}

To cite: Silva ENda, Powell-Jackson T. Does expanding primary healthcare improve hospital efficiency? Evidence from a panel analysis of avoidable hospitalisations in 5506 municipalities in Brazil, 2000-2014. BMJ Glob Health 2017;2:e000242. doi:10.1136/ bmjgh-2016-000242

Received 13 November 2016 Revised 18 April 2017 Accepted 20 April 2017

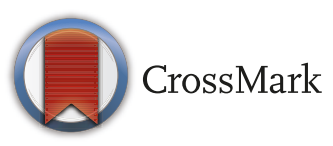

- Additional material is published online only. To view, please visit the journal online (http://dx.doi.org/10.1136/ bmjgh-2016-000242).

${ }^{1}$ Department of Global Health and Development, Faculty of Public Health and Policy, London School of Hygiene and Tropical Medicine, London, UK

${ }^{2}$ Faculty of Ceilandia, University of Brasilia, Brasilia, Brazil

Correspondence to Dr Everton Nunes da Silva; evertonsilva@unb.br

\section{ABSTRACT}

Background Hospitals account for the major share of health expenditure. Primary healthcare may improve efficiency at the hospital level by reducing avoidable admissions. We examined whether rapid expansion of primary healthcare in the context of Brazil's Family Health Strategy (FHS) was associated with a reduction in avoidable hospitalisations.

Methods We constructed panel data for 5506 municipalities over 2000-2014. Our primary outcome was the rate of avoidable hospitalisations, defined with reference to the official list of ambulatory care sensitive conditions (ACSC). The exposure variable was FHS coverage. We used first-difference models at the municipality level, controlling for municipality characteristics and confounding trends. We ran similar models for each of the 19 diseases in the list of ACSCs. Findings FHS coverage expanded from $14 \%$ to $64 \%$ of the population between 2000 and 2014. Over the same period, the rate of avoidable hospitalisations fell from 17 to 10 per 1000 population. Results from the econometric analysis show that the FHS at full coverage was associated with an increase of $0.6(95 \% \mathrm{Cl} 0.3$ to $0.9 ; p<0.001)$ in the rate of avoidable hospital admissions. Expansion of the FHS was associated with an increase of $866(95 \% \mathrm{Cl} 762$ to $970 ; p<0.001$ ) in the rate of primary care consultations. The FHS was not significantly associated with a reduction in hospitalisations for any of the 19 conditions.

Conclusions While high-quality primary healthcare can deliver considerable health benefits to the population, it may not always be effective in addressing inefficiencies at the hospital level due to avoidable admissions.

\section{INTRODUCTION}

Hospitals account for the major share of health expenditure worldwide. According to WHO, half to two-thirds of total government spending on health is allocated to hospital services, and almost US $\$ 300$ billion is wasted annually due to inefficiencies at this level of care. ${ }^{1}$ Inappropriate admissions are an important source of inefficiency. ${ }^{2}$ In the

\section{Key questions}

What is already known about this topic?

- Hospitals in every country absorb considerable resources and policy-makers are looking for ways to improve efficiency.

- Although the evidence is mixed, a number of studies suggest that expanding primary care health can improve hospital efficiency by reducing avoidable admissions.

- Family Health Strategy (FHS) is one of the world's largest community-based primary healthcare programmes, reaching $64 \%$ of the Brazilian population (127 million people) in 2014.

\section{What are the new findings?}

- We found that expansion of primary care through the FHS was not associated with a reduction in avoidable hospitalisations in Brazil.

- The findings suggest that the increase in primary care consultations did not substitute for avoidable hospitalisations; if anything, they facilitated more access to hospitals, perhaps through referrals and increased case detection.

\section{Recommendations for policy}

- The findings challenge the idea that primary healthcare will automatically address hospital inefficiencies through reductions in avoidable hospitalisations.

current economic climate, as health systems are increasingly under pressure to do more with less, the question of how to reduce waste and improve efficiency is at the forefront of policy discussions. ${ }^{3}$

Striking an appropriate balance between primary and hospital-level care has long been proposed as a way to address inefficiency within a health system. ${ }^{2}$ By promoting health, preventing disease and providing timely diagnosis and treatment of certain health 
conditions, primary healthcare can potentially reduce avoidable admissions to allow hospitals to focus resources on more serious complex conditions that require secondary or tertiary care. Conditions for which hospitalisation could potentially be avoided are commonly referred to as ambulatory care sensitive conditions (ACSCs). ${ }^{4}$ They include a set of diseases and health problems for which timely and high-quality primary healthcare should decrease the risk of hospital admission, ${ }^{5}$ such as diseases preventable by immunisation, nutritional deficiencies, diabetes, heart diseases, hypertension, asthma and cerebrovascular diseases.

While the idea of reducing avoidable hospital admissions by expanding quality primary healthcare is plausible, the empirical evidence is mixed, of a low quality and skewed towards high-income countries. A systematic review of the relationship between avoidable hospitalisations and accessibility to primary healthcare assessed 51 studies, of which 37 studies showed a negative association between primary healthcare and admissions due to ACSCs, and 5 studies showed a positive association. ${ }^{6}$ Another systematic review investigated the association between hospitalisation for diabetes-related conditions, one of the largest single categories of ACSCs, and primary healthcare resourcing. The authors found inconclusive results, with only 3 out of 12 studies showing a negative association after adjusting for health status. Finally, a systematic review found that there was considerable geographic variation in avoidable admissions, and that a key driver cited by studies was the quality of primary care. ${ }^{8}$

In this paper, we examined whether primary healthcare reduces avoidable hospitalisations in the context of Brazil's FHS. Introduced in 1994, the FHS expanded to become one of the world's largest community-based primary healthcare programmes. The FHS serves as a natural experiment-it is an ideal testing ground to examine the relationship between primary healthcare and avoidable hospitalisations because expansion was rapid yet implementation varied considerably between municipalities. $^{9}$

\section{METHODS}

\section{Brazil's FHS}

After emerging from dictatorship in 1985, Brazil formally established health as a right for all citizens in the Federal Constitution. It created the Unified Health System (Sistema Único de Saúde), a decentralised public health system that provides universal, comprehensive healthcare, and free of charge at the point of service. ${ }^{10}$ Against this background, the federal government launched the FHS (formerly the Family Health Programme) to deliver a set of individual and collective health actions, including health promotion and protection, disease prevention, diagnosis, treatment, rehabilitation, harm reduction and health maintenance. ${ }^{11}$ The FHS deploys interdisciplinary healthcare teams near to people's home or work to facilitate access and first-contact care. They are composed of at least a physician, a nurse, a nurse assistant, four to six full-time community health agents (professionals from the local community that work together with the community in health promotion and disease prevention actions) and a dentist and dental technicians. ${ }^{12}$

Since its introduction at the national level, the FHS has expanded fairly rapid, particularly in the 2000s, reaching $64 \%$ of the population ( 127 million people) in $2014 .^{13}$ The annual resources devoted to primary healthcare by the Ministry of Health have increased over time, reaching $\mathrm{R} \$ 16.5$ billion ( $£ 4$ billion) in 2014 , which corresponded to $16 \%$ of the federal government expenditure on health. ${ }^{14}$ Studies suggest that the FHS has reduced all-cause mortality, ${ }^{15}$ and mortality from heart and cerebrovascular diseases. ${ }^{16}$ There is also evidence from siblings that children exposed to the FHS in utero were healthier than those not exposed to the programme. ${ }^{17}$

\section{Study design}

We exploited expansion of the FHS to compare changes in avoidable hospitalisation in municipalities where the programme was implemented relative to municipalities where there was limited expansion of the programme. Our approach was akin to the basic difference-in-differences method, except that we had multiple time periods and geographical areas, and used a continuous measure of exposure. ${ }^{18}$ To implement this approach, we applied well-established methods for the analysis of panel data over the period $2000-2014 .{ }^{19}$ We chose the municipality (equivalent to a US county) as the unit of study because it is the administrative level responsible for implementation of the FHS and the lowest level for which data were available on exposure and outcomes.

\section{Data and measures}

We constructed a panel of 5506 municipalities over the period 2000-2014 (see web appendix). We excluded the capital Brasilia because it functions as both a municipality and a state. The study period captured much of the expansion of the programme. Coverage of the FHS was our exposure variable. It measured the proportion of the municipality population covered by the FHS, based on the Ministry of Health norm that one family health team serves 3450 people. Data on the annual number of family health teams in each municipality were obtained from the Brazilian Ministry of Health. ${ }^{20}$

Our primary outcome was the rate of public hospital admissions for ACSCs per 1000 population. It includes admissions at both secondary and tertiary care. We excluded persons aged over 80 years because such individuals were likely to have a high prevalence of comorbities for which treatment at the hospital level may be warranted on clinical grounds. ${ }^{21}$ The official Brazilian Ministry of Health list of ACSC-related diseases provided the basis for our measure of avoidable hospitalisations. ${ }^{22}$ It comprised 19 diseases or health conditions that in principle can be managed effectively at the primary care level (see web appendix). ACSC-related hospital admissions 
corresponded to $24 \%$ of all hospital admissions during the study period.

Secondary outcomes included the number of primary care consultations per 1000 population as a check on whether the FHS improved utilisation of primary healthcare. We also considered additional measures closely related to avoidable admissions. The number of days hospitalised for ACSCs per 1000 population and hospital expenditure for ACSCs per capita captured potential reductions in the use of hospital resources. Consistent with the primary outcome, these measures excluded persons aged over 80 years. Annual data on outcomes for each municipality were extracted from the Hospital Information System known as DATASUS. ${ }^{23}$

We sought to address some of the most important sources of confounding using data on various (timevarying) characteristics of the municipality. In terms of the determinants of health, we controlled for the human development index, Gini coefficient, monthly income per capita, percentage of population below the poverty line and percentage of the population aged 15 years or above who cannot read or write. ${ }^{24}$ For some of these variables, data were not available for every year, in which case we estimated annual values by linear interpolation (see web appendix). In terms of the supply of hospital care, we controlled for the number of public and private hospital beds per 1000 population. ${ }^{25}$ Finally, we included the share of the population by age group to control for demographic trends: 0-4years, 5-19years, $20-59$ years, $60-69$ years, $70-79$ years and over 80 years. ${ }^{23}$

\section{Statistical analysis}

We estimated the mean and SD of variables used in the analysis in 2000 and 2014, as well as the change over time. We further described the data using scatter plots to compare for each municipality the change over time in FHS coverage against the change over time in the rate of primary care consultations and the rate of hospital admissions for ACSCs, respectively.

Our primary analysis was based on an underlying model of the relationship between the FHS and avoidable hospitalisations that included as independent variables: FHS coverage as our measure of exposure, a set of timevarying municipality characteristics, municipality fixed effects, state-year fixed effects and an error term (see web appendix). The municipality fixed effects accounted for unmeasured time-invariant factors such as geographical or historical characteristics, while the state-year fixed effects allowed for confounding trends. The coefficient on the exposure variable provided our estimate of the effect of the FHS on avoidable hospitalisations and other outcomes.

In practice, we estimated the model in first differences, rather than with municipality fixed effects, because the data showed highly persistent shocks as demonstrated by the fact that the standard test for serial correlation rejected the null hypothesis of no serial correlation. ${ }^{19}$ The municipality fixed effects dropped out due to the differencing. We presented both unadjusted estimates (with no municipality controls-model 1 ) and adjusted estimates (with municipality controls-model 2). Each regression was weighted by the municipality population to reveal the effect of the FHS on the average person rather than the average municipality. We clustered standard errors at the municipality level. ${ }^{26}$

We conducted several additional analyses. First, we examined the effect of the FHS on hospital admissions for each of the 19 ACSCs separately and plotted the estimates with 95\% CIs. Second, we explored the extent to which avoidable hospital admissions may have been influenced by expansion of the FHS in other municipalities. We anticipated that such 'spillovers' could arise if people travel across municipality borders to seek hospital care. We used ArcGIS (V.10.3) to identify each municipality's nearest neighbour based on the distance between centroids and extended our main specification to include FHS coverage as well as the characteristics of the nearest neighbour.

We tested the sensitivity of our results to the inclusion of additional covariates and alternative estimation models, ${ }^{19}$ and examined pretrends as a standard diagnostic for bias in panel data models (see web appendix). ${ }^{27}$ We also reported results in which we excluded children aged 0-19years, since this age group accounted for a high portion of the ACSCs (41\% in 2000 and $32 \%$ in 2014). Finally, we conducted a placebo test in which the dependent variable was the rate of hospitalisations due to hip operations. All statistical analyses were conducted using Stata 14.1 SE. The data and code are available on request from the authors.

\section{RESULTS}

FHS coverage expanded substantially from 14\% (7000 teams) in 2000 to $64 \%$ (37 000 teams) of the population in 2014 (table 1, figure 1). Table 1 shows that over the study period, the rate of primary care consultations saw more than a threefold increase from 181 to 654 visits per 1000 population. Meanwhile, the rate of hospitalisations for ACSCs fell from 17 to 10 per 1000 population. Reductions were also seen in hospital days and hospital expenditure related to ACSCs. Changes in the characteristics of municipalities show an improvement in socioeconomic conditions and an ageing population.

Figure 2A shows the relationship between the change in FHS coverage and the change in avoidable hospitalisations. There is no discernable association between the two, with the prediction from a linear regression slightly positive but essentially flat. Figure 2B shows the relationship between the change in FHS coverage and the change in primary care consultations. There is a strong positive relationship, indicating that municipalities that experienced greater increases in FHS coverage had larger increases in the rate of primary care consultations.

Table 2 presents the results from the panel regressions. We find strong evidence of no reduction in avoidable 


\begin{tabular}{|c|c|c|c|}
\hline Variable & 2000 & 2014 & Difference \\
\hline \multicolumn{4}{|l|}{ FHS programme } \\
\hline FHS coverage (teams per 3450 population) & $0.14(0.22)$ & $0.64(0.39)$ & 0.5 \\
\hline \multicolumn{4}{|l|}{ Study outcomes } \\
\hline $\begin{array}{l}\text { Primary care consultations (per } 1000 \\
\text { population) }\end{array}$ & $181(670)$ & $654(1184)$ & 473 \\
\hline $\begin{array}{l}\text { Hospitalisations for ACSC (per } 1000 \\
\text { population) }\end{array}$ & $16.7(11.5)$ & $10.4(8.4)$ & -6.3 \\
\hline Hospital days for ACSC (per 1000 population) & $84.1(45.0)$ & $54.5(26.6)$ & -29.6 \\
\hline Hospital expenditure on ACSC ( $\mathrm{R} \$$ per capita) & $12.9(7.8)$ & $9.3(5.2)$ & -3.6 \\
\hline \multicolumn{4}{|l|}{ Municipality characteristics } \\
\hline Gini coefficient of income inequality & $0.57(0.06)$ & $0.52(0.08)$ & -0.05 \\
\hline Human development index & $0.60(0.11)$ & $0.76(0.07)$ & 0.16 \\
\hline Monthly income per capita & $585(347)$ & $861(443)$ & 276 \\
\hline Below the poverty line & $28.1(21.6)$ & $10.3(13.5)$ & -17.8 \\
\hline Illiteracy & $14.4(11.7)$ & $8.3(7.9)$ & -6.1 \\
\hline Share of population $0-4$ years & $0.10(0.02)$ & $0.07(0.02)$ & -0.03 \\
\hline Share of population 5-19years & $0.31(0.04)$ & $0.25(0.04)$ & -0.06 \\
\hline Share of population 20-59years & $0.51(0.05)$ & $0.55(0.04)$ & 0.04 \\
\hline Share of population $60-69$ years & $0.05(0.01)$ & $0.06(0.01)$ & 0.01 \\
\hline Share of population $70-79$ years & $0.03(0.01)$ & $0.03(0.01)$ & 0 \\
\hline Share of population over 80 years & $0.01(0.00)$ & $0.01(0.01)$ & 0 \\
\hline Hospital beds per 1000 population & $28.8(25.3)$ & $22.4(15.2)$ & -6.4 \\
\hline
\end{tabular}

Values are mean (SD). Expenditures are constant $\mathrm{R} \$$ in 2014 values.

ACSC, ambulatory care sensitive condition; FHS, Family Health Strategy.

admissions due to the FHS. Expansion of the primary care programme from zero to full coverage was associated with a small increase of 0.6 in the rate of hospitalisations for ACSCs $(p<0.001)$. We find that expansion of the FHS was associated with a large increase in utilisation of primary healthcare. The estimate after adjustment for covariates indicates that the FHS was associated with an

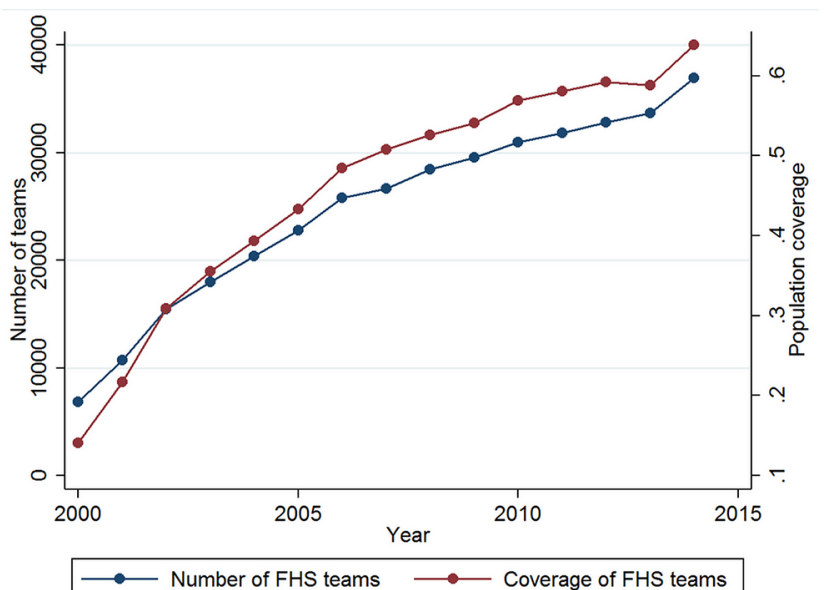

Figure 1 Expansion of the Family Health Strategy (FHS) between 2000 and 2014. increase of 866 visits in the rate of primary care consultations $(\mathrm{p} \leq 0.001)$.

Figure 3 reports the estimates of the effect of the FHS on avoidable admissions for each of the 19 conditions within the list of ACSCs. The effects for most conditions are small and positive; for two conditions only- lung diseases and asthma-are the effects negative but the estimates are not statistically different from zero. The overall effect on avoidable admissions seems to be driven in part by the result for infectious gastroenteritis.

Table 3 shows the effect of FHS on other secondary outcomes. The FHS was associated with an increase of 2.9 in hospital days per 1000 capita $(\mathrm{p}<0.001)$ and an increase of $\mathrm{R} \$ 0.5$ (£0.1) in hospital expenditure per capita $(p<0.001)$. Both estimates were small relative to their respective means in 2014. These results were not driven by increases in the length of stay or expenditure per admission-the FHS had no effect on these two outcomes (see table A3 in the web appendix).

The estimates presented thus far imply that the FHS led to an additional 79000 hospital admissions for ACSCs out of a total of 1.9 million hospital admissions in the entire country in 2014. In the same year, the programme also contributed to an additional 110 million primary care visits, 353000 hospital days 
A

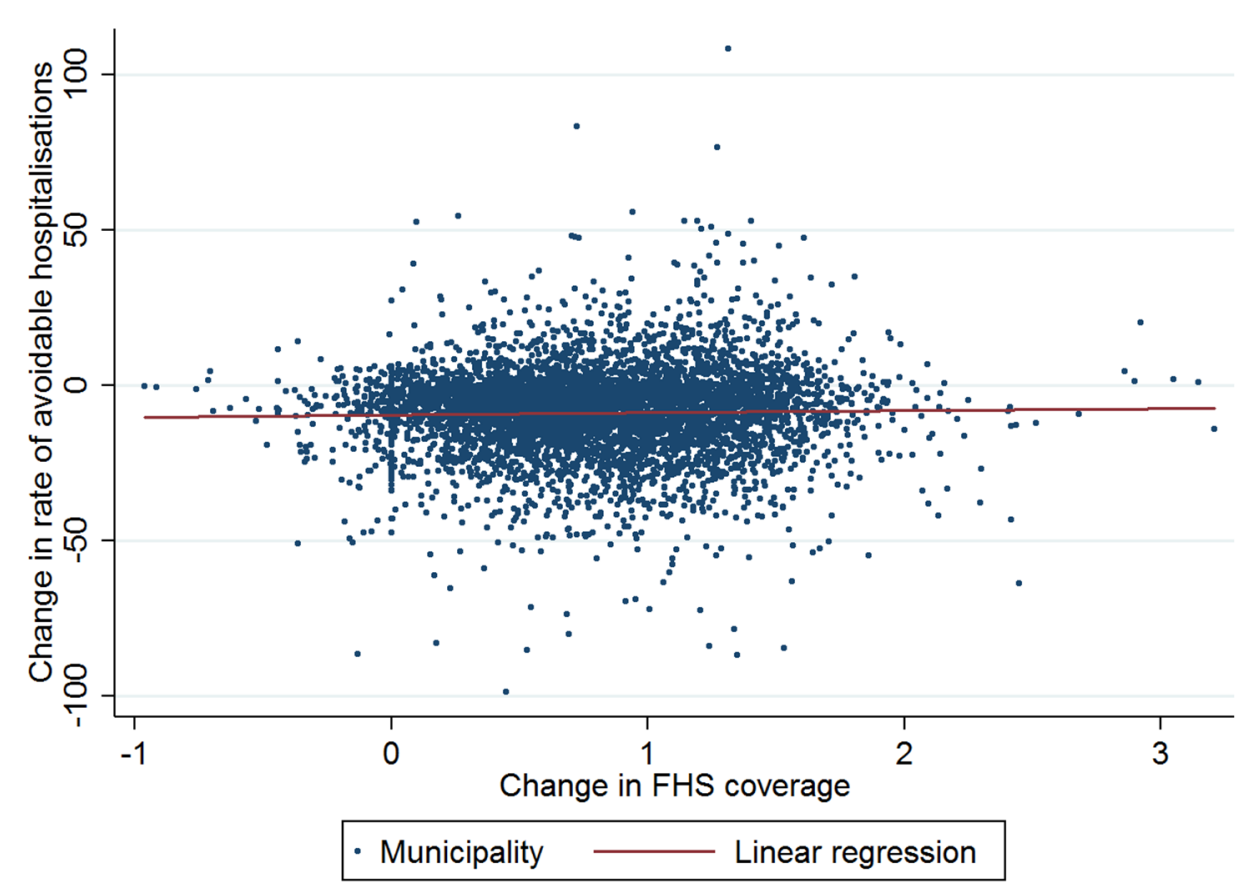

B

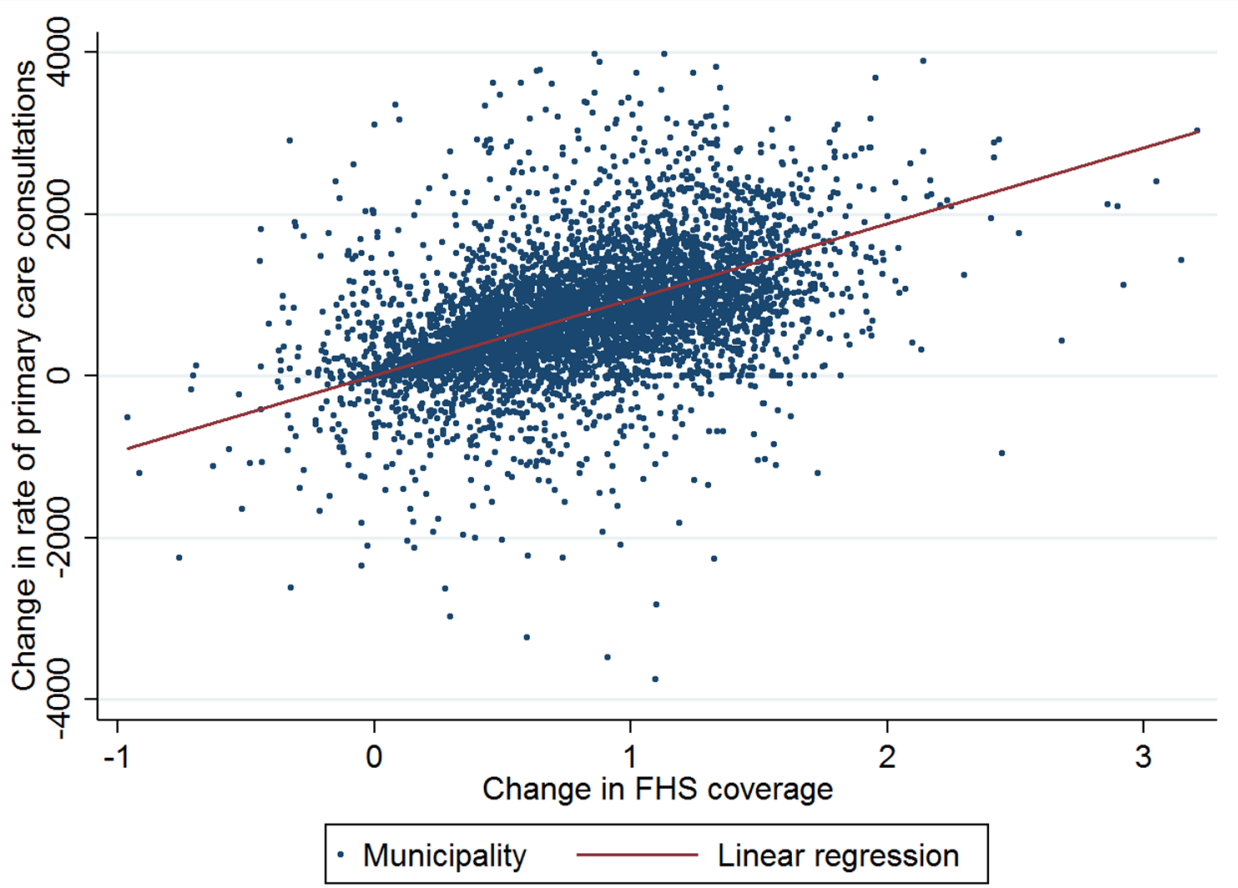

Figure 2 Change in Family Health Strategy (FHS) coverage against change in avoidable hospitalisations (A) and primary care consultations (B).

and $\mathrm{R} \$ 59.7$ million ( $£ 15.5$ million) in hospital expenditure on ACSCs.

We subjected our main result on avoidable hospitalisations to a wide range of robustness tests (see table A4 in the web appendix). The estimate of effect remained the same when we controlled for the political party of the municipality mayor. The results remained qualitatively unchanged when instead of first differencing, we ran fixed effects, random effects and regression models with an autoregressive error structure. When we used 
Table 2 Effect of FHS on primary care consultations and avoidable hospitalisations

\begin{tabular}{|c|c|c|c|c|}
\hline & \multicolumn{2}{|c|}{$\begin{array}{l}\text { Hospitalisations for ACSC (per } 1000 \\
\text { population) }\end{array}$} & \multicolumn{2}{|c|}{$\begin{array}{l}\text { Primary care consultations (per } 1000 \\
\text { population) }\end{array}$} \\
\hline & Model $1(95 \% \mathrm{Cl})$ & Model 2 (95\% Cl) & Model $1(95 \% \mathrm{Cl})$ & Model $2(95 \% \mathrm{Cl})$ \\
\hline FHS coverage & $0.3^{*}(-0.002$ to 0.6$)$ & $0.6^{* * *}(0.3$ to 0.9$)$ & $873^{\star \star \star}$ (769 to 977$)$ & $866^{\star \star \star}$ (762 to 970$)$ \\
\hline Observations & 77084 & 77056 & 77084 & 77056 \\
\hline Municipalities & 5506 & 5504 & 5506 & 5504 \\
\hline Mean (2014) & 10.4 & 10.4 & 654 & 654 \\
\hline
\end{tabular}

Time period is 2000-2014. Cls are shown in parentheses, based on SEs that are clustered by municipality. Data are weighted by the municipality population. Models are estimated in first differences and include state-year fixed effects. Model one presents unadjusted estimates (no covariates). Model two presents adjusted estimates (covariates included).

${ }^{*} \mathrm{p}<0.1 ;{ }^{* *} \mathrm{p}<0.05 ;{ }^{* * *} \mathrm{p}<0.01$

ACSC, ambulatory care sensitive condition; FHS, Family Health Strategy.

2-year and 3-year long differences, rather than annual differences, the positive effect of the FHS on avoidable admissions was slightly larger. Including leads and lags of the exposure variable shows that there were no diverging pretrends to strongly bias the results (see figure 1 in the web appendix). When we excluded children aged 0-19 years, the results were consistent with the main results, showing a small positive effect on avoidable hospitalisations $(\mathrm{p}=0.04$ for model $1 ; \mathrm{p}=0.001$ for model 2). In our placebo test, results showed that there was no measurable effect on hospitalisations for hip operations $(\mathrm{p}=0.400$ for model $1 ; \mathrm{p}=0.344$ for model 2).

Finally, table 4 presents results showing the spillover effect of the FHS on avoidable hospitalisations and utilisation of primary healthcare. Estimates show that expansion of the FHS in the nearest municipality had a small positive effect on hospitalisations for ACSCs $(\mathrm{p}=0.08)$ and no effect on primary care consultations $(\mathrm{p}=0.847)$.

\section{DISCUSSION}

Using a rich panel dataset covering almost every municipality in Brazil over a 15-year period, we examined whether rapid expansion of primary healthcare in the context of the FHS was associated with a reduction in avoidable hospitalisations. We found evidence that the FHS did not reduce avoidable admissions but rather had a small positive effect, with estimates showing a 0.6 increase in the number of avoidable admissions per 1000 capita (roughly $6 \%$ of the mean in 2014). Consistent with this finding, we found small positive effects on closely related outcomes, namely days hospitalised for ACSCs and hospital expenditure on ACSCs, and evidence of a spillover effect. Further results showed that the FHS led to a large increase in primary care consultations-a

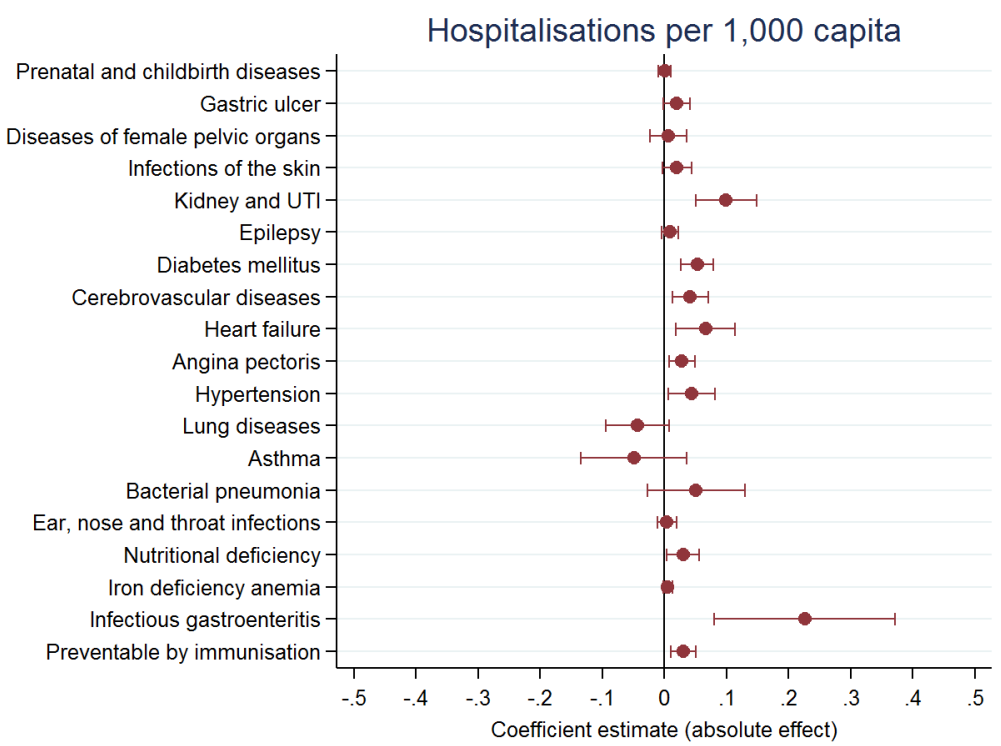

Figure 3 Effect of Family Health Strategy on avoidable hospitalisations by condition. UTI, urinary tract infection. 
Table 3 Effect of FHS on measures of hospital resource use

\begin{tabular}{|c|c|c|c|c|}
\hline & \multicolumn{2}{|c|}{ Hospital days for ACSC (per 1000 population) } & \multicolumn{2}{|c|}{ Hospital expenditure on ACSC (R\$ per capita) } \\
\hline & Model 1 (95\% Cl) & Model 2 (95\% Cl) & Model $1(95 \% \mathrm{Cl})$ & Model $2(95 \% \mathrm{Cl})$ \\
\hline FHS coverage & $1.5^{\star *}(0.008$ to 3.0$)$ & $2.9^{* * *}(1.4$ to 4.4$)$ & $0.2^{* *}(0.2$ to 0.4$)$ & $0.5^{* * *}(0.3$ to 0.7$)$ \\
\hline Observations & 77084 & 77056 & 77084 & 77056 \\
\hline Municipalities & 5506 & 5504 & 5506 & 5504 \\
\hline Mean (2014) & 54.5 & 54.5 & 9.3 & 9.3 \\
\hline
\end{tabular}

Time period is 2000-2014. Cls are shown in parentheses, based on SEs that are clustered by municipality. Data are weighted by the municipality population. Models are estimated in first differences and include state-year fixed effects. Model 1 presents unadjusted estimates (no covariates). Model 2 presents adjusted estimates (covariates included). Expenditures are constant R\$ in 2014 values.

${ }^{*} \mathrm{p}<0.1 ;{ }^{* *} \mathrm{p}<0.05 ;{ }^{* * *} \mathrm{p}<0.01$

ACSC, ambulatory care sensitive condition; FHS, Family Health Strategy.

Table 4 Spillover effect of FHS on avoidable hospitalisations and primary care consultations

\begin{tabular}{lll}
\hline Variable & $\begin{array}{l}\text { Hospitalisations for ACSC (per } 1000 \\
\text { population) }\end{array}$ & $\begin{array}{l}\text { Primary care consultations (per 1000 } \\
\text { population) }\end{array}$ \\
\hline FHS coverage in own municipality & $0.6^{* * *}(0.3$ to 0.9$)$ & $872^{* * *}(769$ to 975$)$ \\
FHS coverage in nearest municipality & $0.07^{*}(0$ to 0.14$)$ & $1.8(-16$ to 20$)$ \\
\hline Observations & 77028 & 77028 \\
Municipalities & 5502 & 5502 \\
Mean (2014) & 10.4 & 654 \\
\hline
\end{tabular}

Time period is 2000-2014. Cls are shown in parentheses, based on SEs that are clustered by municipality. Data are weighted by the municipality population. Models are estimated in first differences. All specifications include state-year fixed effects, characteristics of the index municipality and characteristics of the nearest municipality.

${ }^{*} p<0.1 ;{ }^{* *} p<0.05 ;{ }^{* * *} p<0.01$.

ACSC, ambulatory care sensitive condition; FHS, Family Health Strategy.

finding that is reassuring for our study design given that the relationship is essentially mechanical.

The findings suggest that the increase in primary care consultations did not substitute for avoidable hospitalisations; if anything, they facilitated more access to hospitals, perhaps through referrals and increased case detection. The expansion of primary healthcare was thus unable to reduce the use of unnecessary resources at the hospital level. When viewing these findings, it is important to recognise that reducing avoidable hospitalisations was not the aim of the FHS. We used the natural experiment provided by the FHS to address the question of whether expanding primary healthcare reduced avoidable hospitalisations rather than as a means to evaluate the FHS. There is encouraging evidence suggesting the FHS has improved mortality in the population and such studies are a better reflection of the success of the programme.

Our findings challenge those from previous studies in Brazil. Various analyses have found a negative association between the FHS and avoidable hospitalisations, with estimates ranging from about $5 \%$ to $30 \%$ depending on the outcome, measure of exposure and empirical approach. However, there are various reasons to be concerned about the robustness of previous results. Guanais and Macinko used data over the period 1998-2002 and restricted their sample to $40 \%$ of municipalities and to three groups of ACSC (diabetes, circulatory and respiratory diseases). ${ }^{28}$ Dourado et al used data for the period 1999-2007 and conducted the analysis at the state level even though implementation of the FHS is at the municipality level. ${ }^{21}$ Macinko et al focused on chronic diseases, using data for the period 1999-2007 and an instrumental variable approach that provided no justification for why the exclusion restriction would not be violated.$^{29}$ Finally, Rasella et al estimated the effect of the FHS on hospitalisations for heart and cerebrovascular diseases with a restricted sample of $30 \%$ of municipalities, and did not account for time trends. ${ }^{16}$

We addressed a number of problems that have bedevilled previous efforts. Our analysis used data from almost every municipality in the country over a 15-year time span. We controlled for unobserved time-invariant factors at the municipality level and, importantly, allowed for confounding trends at the state level. We considered the full set of ACSCs when defining our outcomes, although we did show that there was no reduction in avoidable admissions for any single condition. Finally, we dealt appropriately with serial correlation. That said, several limitations of our study should be acknowledged. First, our approach was quasi-experimental and omitted variable bias is always a possibility. However, the wide range of robustness checks and the lack of a negative correlation between changes in FHS coverage and avoidable admissions in the raw data suggest otherwise. Second, we used administrative data to carry out the analysis. Although they are relevant for monitoring and evaluating public policies and their use 
by researchers and decision makers has grown, administrative information systems are also susceptible to reporting or notification errors related to procedures and events. ${ }^{30}$ Third, our data were restricted to the public health system, since there was no available information for the private sector, which delivers health services to $25 \%$ of Brazil's population by means of health insurance. ${ }^{10}$

There are various aspects of how the health system in Brazil functions that provide context behind our findings. Barriers to accessing healthcare facilities, including the shortage of doctors and long waiting times, have long existed, ${ }^{31}$ particularly in rural, remote and vulnerable areas. ${ }^{32}$ There are also barriers to accessing specialised care (secondary and tertiary services) such that patients often seek care directly through hospital emergency services, ${ }^{10}$ which tend to act independently of primary healthcare. ${ }^{33}$ Under these circumstances, the role of the community doctor or general practitioner as a gatekeeper has been limited, reducing scope for promoting appropriate ambulatory care and filtering elective hospital care. Hospitals in Brazil operate at low levels of efficiency, ${ }^{34}$ as has been shown in several studies with 428 and 112 hospitals, respectively. ${ }^{35}$ Factors associated with inefficiency were the size of hospital (almost two-thirds had fewer than 50 beds), low bed occupancy and underutilisation of health professionals. ${ }^{35}$ Moreover, expensive technology is often adopted in municipality hospitals without a strong evidence base or the scale to make it cost-effective. ${ }^{34}$ This problem of course is not peculiar to Brazil. According to WHO, by being more efficient, hospitals could achieve $15 \%$ more than they do currently with the same expenditure. ${ }^{1}$

We do not rule out the possibility that the FHS could contribute to reduced avoidable hospitalisations in the future. Our findings were specific to the period of analysis and it is plausible that avoidable hospitalisations will fall slowly over time as patients increasingly trust and rely on primary health services. It would take time before such results are borne out in the data. Nor do our findings imply that primary health care has been ineffective or of low quality over the period analyzed. In places with the FHS, primary health care probably reached more people with poor health conditions and uncontrolled chronic diseases who did not have access to appropriate healthcare services before the FHS. Greater case detection and diagnosis, ensuring patients enter the public health care system, may have worked against any potential reduction in avoidable hospitalisations. It is beyond the scope of our study to judge the costs and benefits of such actions. Our findings do though raise a number of important questions. First, what policy options might be more successful in reducing avoidable hospitalisations? Gate keeping at the primary care level is an obvious strategy that targets the problem head on. ${ }^{6}$ Financial incentives to primary care providers to reduce referrals are an alternative but are understandably controversial. Instead, some countries such as China are experimenting with patient incentives schemes that, for example, give higher rates of reimbursement for referral cases than for patients who by-pass primary care services. ${ }^{37}$
Second, what was responsible for the downward trend in avoidable hospitalisations between 2000 and 2014? Such a trend is surprising given the demographic, economic and epidemiological changes occurring. Uncovering the reasons may provide useful insights for how to improve hospital efficiency in Brazil.

Contributors All authors conceived and designed the study, did the data analysis, contributed to data interpretation and wrote the manuscript. ENS did the literature search and collected the data. TP-J created the figures.

Funding ENS reported research grant funding from Council for Scientific and Technological Development Programme (CNPq), Brazil, during the conduct of the study. The funder of the study had no role in study design, data collection, data analysis, data interpretation, or writing of the report. The authors had full access to all the data in the study and had final responsibility for the decision to submit for publication.

\section{Competing interests None declared.}

Patient consent Data were publicly available and did not include identifying information on individuals and thus did not require ethics approval.

Provenance and peer review Not commissioned; externally peer reviewed.

Open Access This is an Open Access article distributed in accordance with the Creative Commons Attribution Non Commercial (CC BY-NC 4.0) license, which permits others to distribute, remix, adapt, build upon this work non-commercially, and license their derivative works on different terms, provided the original work is properly cited and the use is non-commercial. See: http://creativecommons.org/ licenses/by-nc/4.0/

(C) Article author(s) (or their employer(s) unless otherwise stated in the text of the article) 2017. All rights reserved. No commercial use is permitted unless otherwise expressly granted.

\section{REFERENCES}

1. World Health Organization. WHO Global Health Expenditure Atlas. World Health Organization, Switzerland 2014 http://www.who.int/ health-accounts/atlas2014.pdf (accessed 18 Jul 2016).

2. World Health Organization. The world health report: health systems financing: the path to universal coverage. World Health Organization, Switzerland $2010 \mathrm{http}: / /$ apps.who.int/iris/bitstream/10665/44371/1/ 9789241564021_eng.pdf (accessed 8 Aug 2016).

3. Ottolini FL, Buggio L, Somigliana E, et al. The complex interface between economy and healthcare: an introductory overview for clinicians. Eur J Intern Med 2016;36:130238-6.

4. Caminal J, Starfield B, Sánchez E, et al. The role of primary care in preventing ambulatory care sensitive conditions. Eur J Public Health 2004;14:246-51.

5. Caminal Homar J, Casanova Matutano C. La Evaluación de la atención primaria y las hospitalizaciones por ambulatory care sensitive conditions. Marco conceptual. Atención Primaria 2003;31:61-5.

6. Rosano A, Loha CA, Falvo R, et al. The relationship between avoidable hospitalization and accessibility to primary care: a systematic review. Eur J Public Health 2013;23:356-60.

7. Gibson OR, Segal L, McDermott RA. A systematic review of evidence on the association between hospitalisation for chronic disease related ambulatory care sensitive conditions and primary health care resourcing. BMC Health Serv Res 2013;13:336.

8. Busby J, Purdy S, Hollingworth W. A systematic review of the magnitude and cause of geographic variation in unplanned hospital admission rates and length of stay for ambulatory care sensitive conditions. BMC Health Serv Res 2015;15:324.

9. Craig P, Cooper C, Gunnell D, et al. Using natural experiments to evaluate population health interventions: new Medical Research Council guidance. J Epidemiol Community Health 2012;66:1182-6.

10. Marten R, Mclntyre D, Travassos C, et al. An assessment of progress towards universal health coverage in Brazil, Russia, India, China, and South Africa (BRICS). Lancet 2014;384:2164-71.

11. Brasil. Ministério da Saúde. Secretaria de Atenção à Saúde. Departamento De Atenção Básica. Política Nacional de Atenção Básica / Ministério da Saúde. Ministério da Saúde, Brasília 2012 http://189.28.128.100/dab/docs/publicacoes/geral/pnab.pdf (accessed 3 Jul 2016). 
12. Macinko J, Harris MJ. Brazil's family health strategy--delivering community-based primary care in a universal health system. $N$ Engl J Med 2015;372:2177-81.

13. Brasil. Ministério da Saúde. Departamento de Atenção Básica. Histórico de Cobertura da Saúde da. Brasilia, Brazil: Departamento de Atenção Básica, 2015. http://dab.saude.gov.br/portaldab/ historico cobertura sf.php (accessed 4 Jul 2016)

14. Áquilas $\bar{M}$, Marques RM. O financiamento da Atenção Básica e da Estratégia Saúde da Família no Sistema Único de Saúde. Saúde debate 2014;38:900-16.

15. Rocha R, Soares RR. Evaluating the impact of community-based health interventions: evidence from Brazil's Family Health Program. Health Econ 2010;19 Suppl:126-58.

16. Rasella D, Harhay MO, Pamponet ML, et al. Impact of primary health care on mortality from heart and cerebrovascular diseases in Brazil: a nationwide analysis of longitudinal data. BMJ 2014;349:94014.

17. Reis M. Public primary health care and children's health in Brazil: evidence from siblings. J Popul Econ 2014;27:421-45.

18. Angrist JD, Pischke JS. Mostly harmless econometrics: an empiricist's companion. Princeton University Press, Princeton 2009.

19. Wooldridge J. Econometric analysis of Cross Section and Panel Data. 2nd Edition. Cambridge: The MIT Press, 2010.

20. Saúde BMda. Secretaria de Atenção à Saúde. Departamento De Atenção Básica. Histórico de Cobertura da Saúde da Familia http:// dab.saude.gov.br/portaldab/historico_cobertura_sf.php (accessed 14 Feb 14 2016).

21. Dourado I, Oliveira VB, Aquino R, et al. Trends in primary health care-sensitive conditions in Brazil: the role of the Family Health Program (Project ICSAP-Brazil). Med Care 2011;49:577-84.

22. Alfradique ME, Bonolo PdeF, Dourado I, et al. Internações por condições sensíveis à atenção primária: a construção da Lista brasileira como ferramenta para medir o desempenho do sistema de saúde (Projeto ICSAP - Brasil). Cad Saude Publica 2009;25:1337-49.

23. Brasil. Ministério da Saúde. Departamento de Informática do Sistema Único de Saúde - DATASUS. Sistema de Informação Hospitalar - SIH http://www.datasus.gov.br/ (accessed 12 Dec 2015).

24. Programa Da Nações Unidas Para Desenvolvimento. Atlas do Desenvolvimento Humano no Brasil http://www.atlasbrasil.org.br/ 2013/pt/consulta/ (accessed 04 Mar 2016).

25. Brasil. Departamento de Informática do Sistema Único de Saúde - DATASUS. Informações de Saúde. Leitos de Internação http:// tabnet.datasus.gov.br/cgi/tabcgi.exe?cnes/cnv/leiintbr.def (accessed 24 Mar 2016).

26. Bertrand M, Duflo E, Mullainathan S. How much should we Trust Differences-In-Differences estimates? Q J Econ 2004;119:249-75.

27. Gentzkow M, Shapiro JM, Sinkinson M. The effect of Newspaper Entry and exit on Electoral Politics. Am Econ Rev 2011;101:2980-3018.

28. Guanais F, Macinko J. Primary care and avoidable hospitalizations: evidence from Brazil. J Ambul Care Manage 2009;32:114-21.

29. Macinko J, Dourado I, Aquino R, et al. Major expansion of primary care in Brazil linked to decline in unnecessary hospitalization. Health Aff 2010;29:2149-60.

30. Xavier DB, Ramalho WM, da Silva EN. Spending on Bariatric Surgery in the Unified Health System from 2010 to 2014: a Study Based on the Specialist Hospitals Authorized by the Ministry of Health. Obes Surg 2017;27:641-8.

31. Garcia-Subirats I, Vargas I, Mogollón-Pérez AS, et al. Barriers in access to healthcare in countries with different health systems. A cross-sectional study in municipalities of central Colombia and north-eastern Brazil. Soc Sci Med 2014;106: 204-13.

32. Santos LM, Costa AM, Girardi SN. Mais Medicos Program: an effective action to reduce health inequities in Brazil. Cien Saude Colet 2015;20:3547-52.

33. Gonçalves MR, Hauser L, Prestes IV, et al. Primary health care quality and hospitalizations for ambulatory care sensitive conditions in the public health system in Porto Alegre, Brazil. Fam Pract 2016;33:238-42.

34. Gragnolati M, Lindelow M, Couttolenc B. Twenty years of health system reform in Brazil: an assessment of the sistema unico de saude. directions in development: human development. Washington: World Bank 2013 http://documents.worldbank.org/curated/en/ 2013/01/17899895/twenty-years-health-system-reform-brazilassessment-sistema-unico-de-saude (accessed 24 Jul 2016).

35. La Forgia GM, Couttolenc BF. Hospital Performance in Brazil: the search for excellence. Washington: World Bank, 2008. https:// openknowledge.worldbank.org/handle/10986/6516. (accessed 24 Jul 2016).

36. Cesconetto A, Lapa JdosS, Calvo MCM. Avaliação da eficiência produtiva de hospitais do SUS de Santa Catarina, Brasil. Cad Saude Publica 2008;24:2407-17.

37. Yip W, Hsiao W. Harnessing the privatisation of China's fragmented health-care delivery. Lancet 2014;384:805-18. 384. 